\title{
Work related symptoms, sensitisation, and estimated exposure in workers not previously exposed to laboratory rats
}

\author{
P Cullinan, D Lowson, M J Nieuwenhuijsen, S Gordon, R D Tee, K M Venables, \\ J C McDonald, A J Newman Taylor
}

\begin{abstract}
Findings are presented from the initial cross sectional phase of a cohort study of employees exposed to laboratory rats. Of 366 eligible workers at four sites 323 $(88 \%)$ were surveyed; symptoms assessed by self completed questionnaire and sensitisation measured by the response to skin prick tests were related to intensity of exposure both to total dust and to rat urinary aeroallergen. Among 238 workers, without previous occupational exposure to rats, work related symptoms, which started after first employment at the site were related to exposure intensity (expressed either in terms of dust or of aeroallergen) at the time of onset of symptoms. These relations were stronger in atopic subjects but were unrelated to smoking. Positive skin tests to rat urinary extract were also more frequent with increased exposure, a relation found in both atopic subjects and in smokers. There was a strong association between work related symptoms and specific sensitisation.
\end{abstract}

(Occup Environ Med 1994;51:589-592)

Keywords: allergen, rat urinary aeroallergen, sensitisation

With exposure-response relations as our main objective, we have undertaken a seven year, longitudinal study of two groups of workers at high risk of developing occupational asthma: those who work with laboratory animals (reported here) and those exposed to flour.

It has been estimated that in the United Kingdom, 32000 workers are regularly in contact with laboratory animals. ${ }^{1}$ Although the incidence of work related asthma in this group is not definitely known, it is likely to be at least $60 / 100000 .^{2}$ Workers with high exposure to rats have been reported to have an increased frequency of allergic disease, ${ }^{3}$ but the detailed nature of the relation between risk and the intensity, timing, and duration of exposure has not been defined. Additional factors, such as atopy, ${ }^{4}$ cigarette smoking, ${ }^{5}$ and exposure to other respiratory irritants may also modify the effects of exposure to allergens and determine outcome. Published studies to date have usually been cross sectional in design or have had sparse exposure information; the current cohort study was designed to correct these deficiencies. We report findings of the initial phase.

\section{Subjects and methods}

SURVEY METHODS

Four institutions specialising in small animal research in the United Kingdom were identified: three use a variety of animals including rats; the fourth uses almost exclusively mice and is not described in this paper. All full time employees in occupational groups where exposure to laboratory rats or mice was probable and a group of non-exposed office workers, who had started work at the site from 1 January 1986 onwards and had worked for at least one month, were invited to participate.

Members of the cohort still employed at the sites have been surveyed at six-monthly intervals since 1990 . We describe the findings from the initial survey. Two visits to each site were made, the second to collect information from those missed at the first visit. Of 366 eligible subjects $323(88 \%)$ were surveyed, with no difference in response rates between the three workforces. Questionnaires were completed by 315 subjects ( $84 \%$ ) and skin prick tests by $295(78 \%)$.

\section{Questionnaire}

The following symptoms, if present since 1986, were recorded with dates of onset: chest tightness, wheeze or difficulty in breathing (chest symptoms), itching of the eyes or nose, running or blockage of the nose or sneezing (eye and nose symptoms), and itchy rash. Symptoms were considered to be work related if it was stated that they had improved over weekends or on holidays of a week or more, or if they were reported by the subject as being provoked by contact with laboratory rats. Symptoms reported to have started after first employment at the site were considered as new.

Full histories of smoking were obtained but for the present analysis subjects were divided into those who had and those who had not smoked at least one cigarette a day for as long as a year at least part of which had been during their employment at the site.

\section{Skin tests}

Skin prick tests were carried out in a standard manner and considered positive if the mean wheal diameter was at least $3 \mathrm{~mm}$ greater than 
Table 1 Characteristics of participants by exposure intensity category at time of survey

\begin{tabular}{|c|c|c|c|c|c|c|c|}
\hline & \multicolumn{4}{|l|}{ Dust } & \multicolumn{3}{|c|}{ Aeroallergen } \\
\hline & Total & Low & Medium & High & Low & Medium & High \\
\hline $\begin{array}{l}\text { Exposure intensity } \\
\text { No (\%) } \\
\text { No men (\%) } \\
\text { Age (median y) } \\
\text { Employed (median months) } \\
\text { Atopic (\%) } \\
\text { Smoking (\%) }\end{array}$ & $\begin{array}{l}238 \\
76(32) \\
24 \\
21 \\
88(40) \\
70(30)\end{array}$ & $\begin{array}{l}\leqslant 0 \cdot 32 \\
87(37) \\
23(26) \\
26 \\
20 \\
22(28) \\
28(33)\end{array}$ & $\begin{array}{l}0 \cdot 33-0 \cdot 34 \\
79(34) \\
25(32) \\
24 \\
20 \\
37(51) \\
18(23)\end{array}$ & $\begin{array}{l}>0 \cdot 34 \\
69(29) \\
27(39) \\
20 \\
24 \\
27(42) \\
23(34)\end{array}$ & $\begin{array}{l}<1 \cdot 0 \\
73(31) \\
12(16) \\
26 \\
16 \\
20(30) \\
28(40)\end{array}$ & $\begin{array}{l}1 \cdot 0-30 \cdot 0 \\
113(48) \\
42(37) \\
24 \\
21 \\
48(47) \\
26(23)\end{array}$ & $\begin{array}{l}>30 \cdot 0 \\
49(21) \\
21(43) \\
20 \\
26 \\
18(38) \\
15(31)\end{array}$ \\
\hline
\end{tabular}

${ }^{\star}$ Geometric mean of total dust $\left(\mathrm{mg} / \mathrm{m}^{3}\right)$ and aeroallergen $\mu \mathrm{g} / \mathrm{m}^{3}$.

that to an inert control solution (1908 Bencard). Subjects were defined as atopic if they had one or more positive tests to three common allergens (B2 grass pollens 4100, Bencard; cat fur 3204, Bencard; and Dermatophagoides pteronyssinus 2801, Bencard). Also, tests were made with an extract of rat urine (1 $\mathrm{mg} / \mathrm{ml}$ ) dialysed in Visking tubing (Medicell International London, molecular weight cut off 12-14 Da) against four changes of distilled water over 48 hours.

\section{Exposure assessment}

A complete work history with job titles and dates was obtained from each subject by a self completed questionnaire, including information on occupational exposure to laboratory rats before their present employment.

Exposure measurements were made directly in a sample of workers in each occupational group over whole shifts with personal air samplers. Details of the sampling and measurements are reported elsewhere. ${ }^{6}$ The samples were assayed gravimetrically for total dust and by radio-allergosorbent test inhibition for rat urinary aeroallergen (RUA). ${ }^{7}$

For the following analyses, occupational groups were aggregated into three roughly equal sized categories of exposure intensity according to current concentrations of either total dust or RUA. Occupations in the highest categories were those with frequent and direct contact with rats (including animal technicians and cage cleaners); medium exposures were experienced by those with less frequent and indirect contact, such as scientists and maintenance staff. In general, dust and aeroallergen measurements correlated well, with groups almost all in the same exposure category whether based on dust or aeroallergen. ${ }^{6}$

\section{Analysis}

Because the focus of the study was the relation between new work related symptoms and exposure, subjects with previous occupational exposure to laboratory rats were excluded. Comparisons of continuous data not normally distributed were made by the Wilcoxon rank sum test, and proportions analysed with the $\chi^{2}$ (or Fisher's exact) test. Trends across exposure categories were assessed by the $\chi^{2}$ test for trend. The main measure of dust or aeroallergen exposure used was intensity category, either at the time of survey or at the time of onset of symptoms. The effects of exposure intensity independent of age, sex, atopy and smoking were examined by stepwise logistic regression. Half a case was substituted into exposure intensity categories that contained no symptomatic subjects.

\section{SUBJECT CHARACTERISTICS}

Of the 323 participants, 72 (22\%) reported previous occupational exposure to laboratory rats and in a further $13(4 \%)$ this information was not available. Table 1 shows some characteristics of the remaining 238 employees. Employees in high intensity categories tended to be younger, but had longer durations of employment at the site. Men (47\%) were more likely than women (37\%) to be atopic and less likely to be smokers (26\% v 32\%). Although workers in the middle exposure categories were most often atopic and least likely to smoke, there was little overall difference in the frequencies of smoking among atopic (28\%) and non-atopic (31\%) employees.

Those with known previous occupational exposure to laboratory rats were on average older (median age 28 years) but had a similar duration of employment at the site $(22$ months). There were fewer smokers (24\%) although a similar proportion were atopic $(40 \%)$. At the time of survey most were in the middle exposure intensity categories, many being research scientists.

\section{Results}

SYMPTOMS AND SKIN TEST RESULTS

Among all surveyed workers 98 (31\%) reported at least one work related symptom. Eye and nose symptoms were the most frequently reported $(22 \%)$, followed by skin $(15 \%)$, and then chest symptoms $(10 \%)$.

Table 2 shows the distribution of new work

Table 2 Frequency of work related symptoms and positive skin tests by exposure intensity category at time of survey

\begin{tabular}{|c|c|c|c|c|c|c|c|c|c|}
\hline \multirow{2}{*}{$\begin{array}{l}\text { New work } \\
\text { related } \\
\text { symptoms }\end{array}$} & \multicolumn{5}{|l|}{ Dust } & \multicolumn{4}{|c|}{ Aeroallergen } \\
\hline & Total & Low & Medium & High & $P$ value & Low & Medium & High & $P$ value \\
\hline $\begin{array}{l}\text { Chest } \\
\text { Eye and nose } \\
\text { Skin } \\
\text { Positive skin }\end{array}$ & $\begin{array}{l}17(7) \\
32(14) \\
25(11) \\
21(10)\end{array}$ & $\begin{array}{l}3(4) \\
8(9) \\
1(1) \\
3(4)\end{array}$ & $\begin{array}{r}8(10) \\
10(13) \\
13(16) \\
9(12)\end{array}$ & $\begin{array}{r}5(7) \\
13(19) \\
10(15) \\
9(14)\end{array}$ & $\begin{array}{l}0.292 \\
0.074 \\
0.004 \\
0.033\end{array}$ & $\begin{array}{c}2(3) \\
11(15) \\
2(3) \\
2(3)\end{array}$ & $\begin{array}{l}12(11) \\
12(11) \\
14(12) \\
13(13)\end{array}$ & $\begin{array}{l}2(4) \\
8(17) \\
8(17) \\
6(13)\end{array}$ & $\begin{array}{l}0.534 \\
0.933 \\
0.010 \\
0.059\end{array}$ \\
\hline
\end{tabular}

Numbers in parentheses are percentages of totals at risk in each column. 
Table 3 Frequency of new, work related symptoms by exposure intensity category at time of onset

\begin{tabular}{|c|c|c|c|c|c|c|c|c|c|}
\hline \multirow{2}{*}{$\begin{array}{l}\text { New work } \\
\text { related } \\
\text { symptoms }\end{array}$} & \multicolumn{5}{|l|}{ Dust } & \multicolumn{4}{|c|}{ Aeroallergen } \\
\hline & Total & Low & Medium & High & Pvalue & Low & Medium & High & Pvalue \\
\hline $\begin{array}{l}\text { Chest } \\
\text { Eye and nose } \\
\text { Skin }\end{array}$ & $\begin{array}{l}17(7) \\
32(14) \\
25(11)\end{array}$ & $\begin{array}{l}2(2) \\
7(8) \\
1(1)\end{array}$ & $\begin{array}{c}7(9) \\
10(13) \\
13(16)\end{array}$ & $\begin{array}{r}8(11) \\
15(21) \\
11(16)\end{array}$ & $\begin{array}{l}0.029 \\
0.017 \\
0.002\end{array}$ & $\begin{array}{l}0(0) \\
9(13) \\
2(3)\end{array}$ & $\begin{array}{l}13(11) \\
14(12) \\
14(12)\end{array}$ & $\begin{array}{l}4(8) \\
9(18) \\
9(18)\end{array}$ & $\begin{array}{l}0.051 \\
0.422 \\
0.005\end{array}$ \\
\hline
\end{tabular}

Numbers in parentheses are percentages of totals at risk in each column.

related symptoms and of positive skin tests among the 238 employees without previous occupational exposure; 50 workers (21\%) reported at least one symptom, most often eye and nose symptoms. About half of those with new symptoms of any particular type reported that these were isolated symptoms; five subjects reported new, work related chest symptoms unaccompanied by other symptoms. Six subjects reported all three symptom patterns. Twenty one $(10 \%)$ subjects had positive skin tests to RUA.

In one employee new work related chest symptoms had started within a month of first employment at the site. The median duration of employment before symptoms started in the remainder was 365 days (range 59-1369). Two with new eye and nose symptoms and five with skin symptoms reported an onset of symptoms within one month. In the rest the median durations of employment before symptoms started were $214(30-976)$ and 335 (30-1218) days respectively. Of those reporting more than one new, work related symptom there was little consistency in which symptom started first, although in only one instance were chest symptoms reported to have started first. New work related chest symptoms were less frequent among workers with previous occupational exposure $(4 \%)$ but there was little difference in the frequency of either eye and nose $(11 \%)$ or skin symptoms (11\%). A higher proportion (18\%) of this group had positive skin tests to RUA.

\section{EXPOSURE INTENSITY}

There was little consistent evidence of a relation between new work related symptoms and exposure intensity at the time of survey (table 2). Positive skin tests to RUA, however, were significantly more common in high exposure

Table 4 Skin prick test results by presence of new work related symptoms

\begin{tabular}{|c|c|c|c|c|c|c|}
\hline & \multicolumn{2}{|l|}{ Chest } & \multicolumn{2}{|c|}{ Eye and nose } & \multicolumn{2}{|l|}{ Skin } \\
\hline & + & - & + & - & + & - \\
\hline $\begin{array}{l}\text { Skin test to } \\
\text { rat urine: } \\
+ \\
-\end{array}$ & $\begin{array}{r}10(63) \\
6(37)\end{array}$ & $\begin{array}{r}11(5) \\
192(95)\end{array}$ & $\begin{array}{r}7(23) \\
24(77)\end{array}$ & $\begin{array}{c}13(7) \\
175(93)\end{array}$ & $\begin{array}{r}7(30) \\
16(70)\end{array}$ & $\begin{array}{c}14(7) \\
182(93)\end{array}$ \\
\hline
\end{tabular}

Numbers in parentheses are percentages of totals at risk in each column. categories of either dust or aeroallergen. Table 3, in contrast, shows the relations between new work related symptoms and exposure at the time of onset. For each type of symptom there was a trend of increasing prevalence with increasing intensity, statistically strongest for skin symptoms. No subjects developed work related chest symptoms while in the low aeroallergen intensity category. The patterns were essentially unchanged after exclusion of those whose symptoms started within a month of first employment.

These findings probably reflect the movement of employees between different occupations at each site. Those with new work related chest symptoms were more likely (24\%) to have moved between exposure categories during employment at the site than were those with eye and nose $(16 \%)$ or skin (12\%) symptoms or those without new work related symptoms of any sort (4\%). All symptomatic workers who moved categories after the start of their symptoms, did so to one of a lower intensity; this was not always true of those without symptoms.

Table 4 shows the association between symptoms and skin test results. There was a close relation between new work related chest symptoms and a positive skin test to rat urine $(P<0.001)$; similar associations were found for those with new work related eye and nose $(P=0.012)$ or skin $(P=0.002)$ symptoms.

\section{ATOPY AND SMOKING}

New work related chest or skin symptoms were more common among atopic subjects (table 5) but there was little difference in the frequency of eye and nose symptoms. Chest and eye and nose symptoms were more common in smokers. The pattern of increasing symptom frequency was maintained when atopic subjects were examined separately. Positive skin tests were strongly related to atopy and to smoking at all levels of exposure (fig).

\section{REGRESSION ANALYSIS}

Regression analysis confirmed an independent effect of aeroallergen exposure on new work related skin symptoms: the odds ratio $(95 \%$

Table 5 Frequency of new, work related symptoms and of positive skin tests by intensity category of rat urinary aeroallergen at time of onset of symptoms or at time of survey (skin tests): by atopy and by smoking

\begin{tabular}{|c|c|c|c|c|c|c|c|c|c|c|c|c|c|c|c|c|}
\hline & \multicolumn{4}{|l|}{ Atopic } & \multicolumn{4}{|c|}{ Non-atopic } & \multicolumn{4}{|c|}{ Smoking } & \multicolumn{4}{|c|}{ Non-smoking } \\
\hline & Total & Low & Medium & High & Total & Low & Medium & High & Total & Low & Medium & High & Total & Low & Medium & High \\
\hline $\begin{array}{l}\text { Chest } \\
\text { Eye and nose } \\
\text { Skin } \\
\text { Positive skin test }\end{array}$ & $\begin{array}{l}12(14) \\
12(14) \\
12(14) \\
19(22)\end{array}$ & $\begin{array}{l}0(0) \\
2(11) \\
1(5) \\
2(10)\end{array}$ & $\begin{array}{r}8(16) \\
7(14) \\
6(13) \\
12(25)\end{array}$ & $\begin{array}{l}4(20) \\
3(17) \\
5(26) \\
5(28)\end{array}$ & $\begin{array}{c}4(3) \\
19(14) \\
11(8) \\
2(2)\end{array}$ & $\begin{array}{l}0(0) \\
7(15) \\
1(2) \\
0(0)\end{array}$ & $\begin{array}{l}4(7) \\
6(11) \\
6(11) \\
1(2)\end{array}$ & $\begin{array}{l}0(0) \\
6(21) \\
4(14) \\
1(3)\end{array}$ & $\begin{array}{c}6(9) \\
11(16) \\
7(10) \\
9(14)\end{array}$ & $\begin{array}{l}0(0) \\
5(19) \\
1(4) \\
1(4)\end{array}$ & $\begin{array}{l}4(15) \\
5(19) \\
5(19) \\
4(17)\end{array}$ & $\begin{array}{l}2(13) \\
1(7) \\
1(7) \\
4(29)\end{array}$ & $\begin{array}{l}11(7) \\
21(13) \\
18(11) \\
12(8)\end{array}$ & $\begin{array}{l}0(0) \\
4(10) \\
1(2) \\
1(3)\end{array}$ & $\begin{array}{l}9(10) \\
9(10) \\
9(10) \\
9(11)\end{array}$ & $\begin{array}{l}2(6) \\
8(24) \\
8(24) \\
2(6)\end{array}$ \\
\hline
\end{tabular}



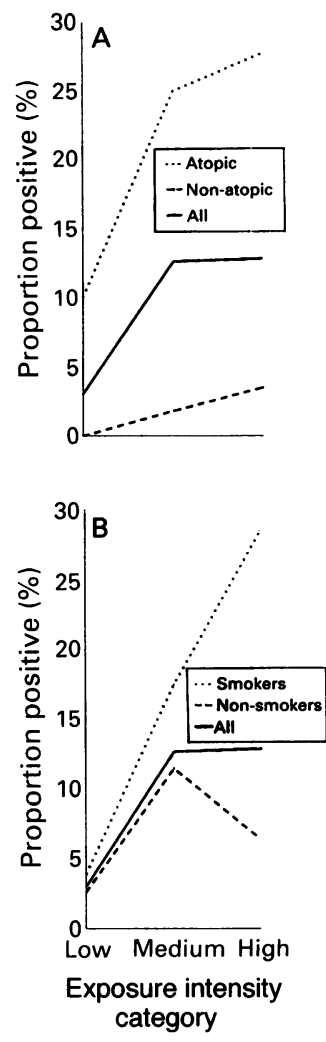

Proportions of subjects with positive skin tests to rat urinary aeroallergen $(A)$ by atopy and (B) by smoking confidence interval $(95 \% \mathrm{CI})$ ) for medium intensity exposure was $5 \cdot 2(1 \cdot 1-24 \cdot 7)$ and for high intensity $10 \cdot 0(2 \cdot 0-50 \cdot 2)$. No independent effect of aeroallergen intensity was found for chest or eye and nose symptoms. When exposure was expressed in terms of total dust, high intensity exposure was related to the development of eye and nose symptoms (3.4, 1.2-9.0) and both medium (14.9, 1.8-121) and high (18.4, 2.3-150) exposures were related to skin symptoms. The strong independent relation between atopy and the presence of a positive skin test to rat urine was confirmed by regression (odds ratio 18.9, 95\% CI 4·2-84·2).

\section{Discussion}

Unlike most cross sectional studies the present analysis was of workers first employed after a specified date. The study is also unusual in the detailed nature of its exposure measurements (although so far used only semiquantitatively) and in that exposure to both dust and aeroallergen have been measured. Workers with previous occupational exposure to laboratory rats, about which there can be less confidence, were excluded from this analysis and emphasis placed on new cases as the best measure of incident work related disease.

None the less, the findings should be interpreted in the light of possible survivor bias, including the potential for employees with occupational disease to have left the site at a different rate from those without such disease. The results provide some insight into this process: workers with previous occupational exposure to rats had a lower prevalence of new work related chest symptoms but the same frequency of other symptoms, and were twice as likely to have a positive skin test to rat urinary allergen, suggesting that the development of asthmatic symptoms is a particularly important determinant of continuing exposure. Movements between jobs with different exposures within each site were accounted for by examining exposures at the time of onset of new symptoms; the findings imply that symptomatic laboratory animal workers tend, after the development of symptoms (and especially symptoms of the lower respiratory system), to move to jobs of lower intensity.

Despite the short exposures experienced by this population, the overall prevalences of work related symptoms were similar to those measured in earlier cross sectional surveys. ${ }^{248}$ This confirms that in susceptible workers allergic symptoms develop soon after first exposure. ${ }^{49}$ The duration of employment before the start of work related chest symptoms in the current group was longer than that for other types of symptom. A high proportion of subjects reported such symptoms in isolation from eye and nose or skin symptoms, unlike earlier surveys where asthma was not reported separately from either rhinitis or skin symptoms. ${ }^{14}$ This discrepancy might be attributable to different selection pressures in the populations studied, or to different disease definitions, but may also reflect a more complex relation between various allergic symptoms, rather than that asthma is the end stage of laboratory animal allergy. ${ }^{10}$

There is good evidence that urinary proteins are responsible for laboratory animal allergy, ${ }^{11}$ but few attempts have been made to examine the nature of any exposure-response relation. Bland $e t a l^{12}$ reported that the risk of allergic disease increased in workers exposed to a variety of animals in relation to the time spent per week in handling the animals; this association was confined to those in low or medium intensity jobs. Kibby et $a l^{3}$ showed that the prevalence of allergy to laboratory animals was positively associated with current intensity of exposure to airborne rat urinary allergen. Neither of these cross sectional studies attempted to examine incident disease. Botham et al, on the other hand, in a prospective study of workers employed for at least nine months, reported that the incidence of allergic disease fell after the introduction of measures designed to reduce exposure. ${ }^{9} \mathrm{~A}$ clear relation between the development of work related symptoms and the intensity of exposure at the time of onset was shown in our study; this was equally true for intensity measured in terms of total dust or of RUA. The detailed nature of this relation with exposure expressed in terms of average and peak intensity, duration, and timing, will be examined more closely in the longitudinal phase of the study.

This study was supported by grants from the National Asthma Campaign, the Health and Safety Executive, and the Royal Society.

We gratefully acknowledge the assistance of Roger Blanks, We gratefully acknowledge the assistance of Roger Blanks,
Mark Divitini, Bernard Graneek, James Hayes, Cath Hogg, Gillian Lamond, and Keith Sullivan; of the study participants; and of the management at each of the sites.

1 Cockroft A, Edwards J, McCarthy P, Andersson N. Allergy in laboratory animal workers. Lancet 1981;i: 827-30.

2 Meredith S, Taylor V, McDonald JC. Occupational respiratory disease in the United Kingdom: :a report to the British Thoracic Society and the Society of Occupational British Thoracic Society and the Society of Occupational
Medicine by the SWORD Project Group. Br $\mathcal{F}$ Ind Med Medicine by the

3 Kibby T, Powell G, Cromer J. Allergy to laboratory animals: a prospective and cross-sectional study. $f$ Occup Med 1989;31:842-6.

4 Venables KM, Tee RD, Hawkins R, et al. Laboratory animal allergy in a pharmaceutical company. $B r \mathcal{F}$ Ind $M e d$ 1988;45:660-6.

5 Venables KM, Upton J, Hawkins R, Tee RD, Longbottom J, Newman Taylor AJ. Smoking, atopy, and laboratory animal allergy. $B r \mathcal{F}$ Ind Med 1988;45:667-71.

6 Nieuwenhuijsen M, Gordon S, Tee RD, Venables KM McDonald JC, Newman Taylor AJ. Exposure to dust and rat urinary aeroallerens in research establishments. Occup Environ Med 1994;51:593-6.

7 Gordon S, Tee RD, Lowson D, Wallis J, Newman Taylor AJ. Reduction of airborne allergenic urinary proteins AJ. Reduction of airborne allergenic urinary prote
from laboratory rats. $B r \mathcal{F}$ Ind Med $1992 ; 49: 416-22$.

8 Slovak A, Hill R. Laboratory animal allergy: a clinical survey of an exposed population. Br f Ind Med 1981;38: $38-41$.

9 Botham P, Davies G, Teasdale E. Allergy to laboratory animals: a prospective study of its incidence and of the influence of atopy on its development. $\mathrm{Br} \mathcal{F}$ Ind $\mathrm{Med}$ 1987;44:627-32

10 Hunskarr $S$, Fosse $R$. Allergy to laboratory mice and rats: a review of the pathophysiology, epidemiology and clinical aspects. Lab Anim 1990;24:358-74.

11 Newman Taylor AJ, Longbottom J, Pepys J. Respiratory allergy to urine proteins of rats and mice. Lancet 1977; ii:847-9.

12 Bland $S$, Levine $M$, Wilson $D$, Fox $N$, Rivera J. Occupational allergy to laboratory animals: an epidemiologic study. F Occup Med 1986;28:1151-7. 